\title{
New data on the status of the jungle cat (Felis chaus Schreber, 1777) in Azerbaijan
}

\author{
Nikolai Spassov ${ }^{1}$, Elshad Askerov ${ }^{5}$, , Assen Ignatov $^{2}$, Ilya Acosta-Pankov ${ }^{3}$
}

National Museum of Natural History, Bulgarian Academy of Sciences, 1 Tsar Osvoboditel Blvd, 1000 Sofia, Bulgaria,

(1)nspassov@nmnhs.com; https://orcid.org/0000-0002-2891-7457

(2)ignatov@nmnhs.com; https://orcid.org/0000-0003-0922-8098

(3) ilya.acosta@nmnhs.com; https://orcid.org/0000-0001-7275-0482

(4) WWF Azerbaijan, 6th Boyuk Gala dongesi 11, Sabay1l rayon, 1001 Baku, Azerbaijan, easkerov@wwfcaucasus.org (5) Institute of Zoology of Azerbaijan National Academy of Sciences, Block 504, pass 1128, A. Abbaszade 13, 1073 Baku, Azerbaijan

(6) Ilia State University, Cholokashvili Ave 3/5, 0162 Tbilisi, Georgia

\begin{abstract}
The article presents new data on the status of the jungle cat (Felis chaus) in Azerbaijan, a species from the Red Data Book of Azerbaijan.
\end{abstract}

Keywords: Azerbaijan, Felis chaus, Transcaucasia

The jungle cat Felis chaus is an Asian species (Fig. 1), reaching Egypt to the east and the European Caucasian region to the north. In Europe, F. chaus is of marginal occurrence: the northern periphery of the species area is related to the European/Asian boundary with small populations in the Cis-Caspian region and the Caucasus along the Caspian Sea. In this region (Caucasus and Transcaucasus), the population has been rapidly declining since the 1960s, mainly with the destruction of the habitats and there were no records of this species in the Astrakhan State Reserve (Russian Federation) since the 1980s (Gray et al., 2016). The estimated numbers were about 100 and 300 animals in Dagestan (Russian Federation) between 2009 and 2013 (Yarovenko, 2014). Little is known about the population status and ecology of the species in Turkey, where this felid is considered threatened by many negative factors (Ogurlu et al., 2010; Ünal \& Eryilmaz, 2020). The species is included in the Red Data Books of the Russian Federation, Armenia and Georgia (Gray et al., 2016). It is included also in the Red Data Book of
Azerbaijan (Qasimova, 2013). The status of the species in these areas is unclear. The species inhabits mainly reed massifs, dense and prickly bush and forest vegetation near reservoirs, but is also found in foothill and lowland forests and rocky areas (Hajiyev \& Rakhmatullina, 2000; Yarovenko, 2014).

Camera traps caught in 2019 and 2020 the presence of the northern subspecies Felis chaus chaus in the Korchay (Fig. 2a) and Turyanchay Reserves (Fig. 2b), in the southern and northern part of the Mingachevir Reservoir (Northern Azerbaijan). The camera traps were installed as part of a research carried out between the Institute of Zoology at the Azerbaijan National Academy of Sciences, WWF-Azerbaijan and the National Museum of Natural History, Bulgarian Academy of Sciences. This field study started in 2018. It is related to the study of the status of rare and endangered carnivores in Transcaucasia and includes also the leopard and the striped hyena (Spassov et al., 2020). Our team registered traces of the jungle cat (2018) in the Hyrkan National Park (40 358 ha) of the Talish Moun- 


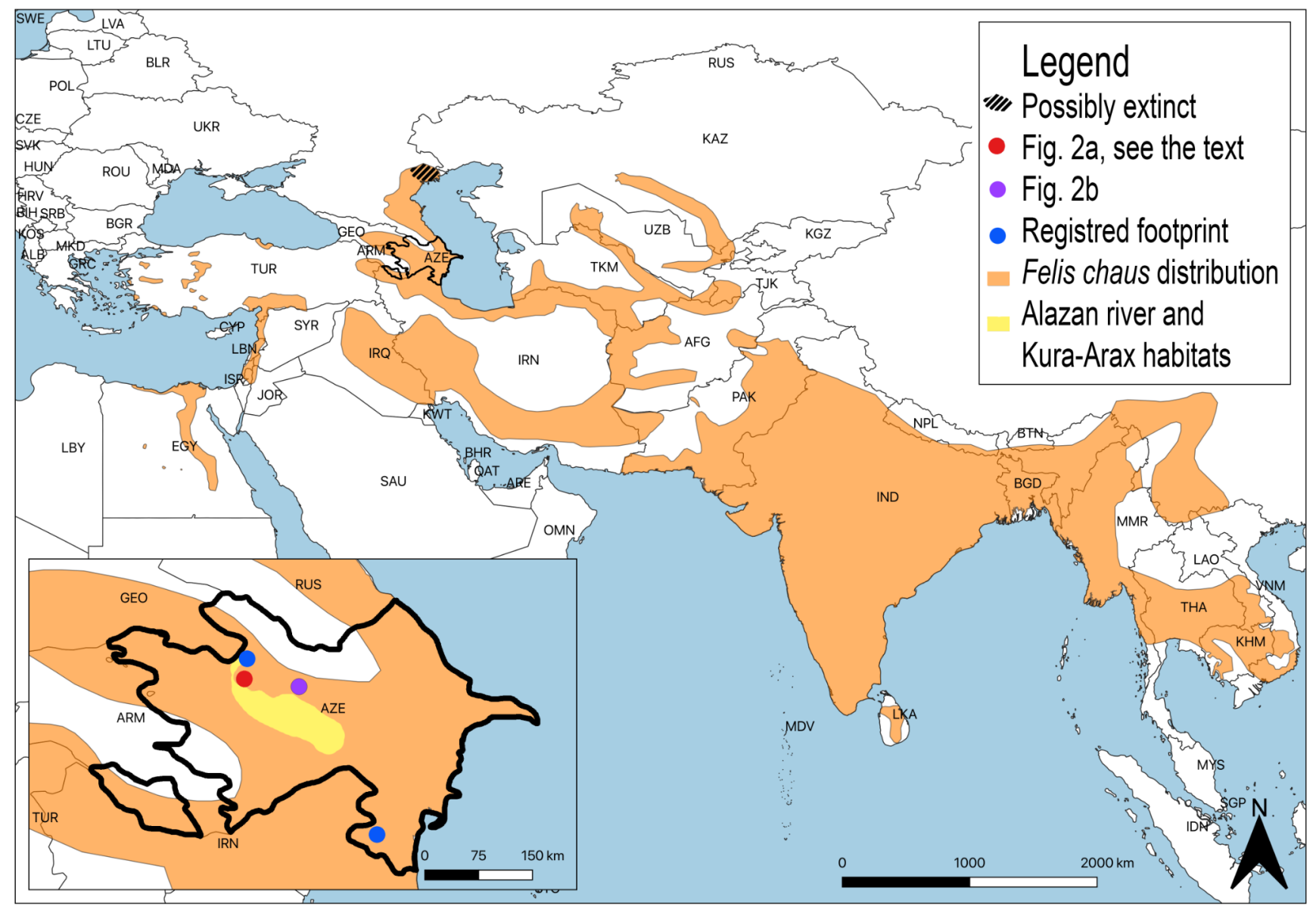

Fig. 1. Area of distribution of Felis chaus (after Gray et al., 2016 with additions and modifications).

tains (SW Azerbaijan) at an altitude of $1200 \mathrm{~m}$ a.s.1., which is the maximum altitude known for this species in the Caspian region (Yarovenko, 2014). Eighteen camera traps installed in the Hyrkan NP (11 in the southern part and 7 in the northern) at the elevation of 1000-1200 $\mathrm{m}$ a.s.1. in southern and $200 \mathrm{~m}$ a.s.1. in the northern part during the period March 2018 - December 2019 (3950 camera/days: 2930 in the southern and 1020 in the northern parts of the park) have captured 13 mammalian species. The jungle cat is one of the numerous species of the Hyrkan NP and its population number has been estimated at 194 individuals, with population density of 6.7 animals per 1000 ha, according to recent analyses of WWF-Azerbaijan.

Besides in the Hyrkan forests, the jungle cat is quite common in Kura-Arax Lowland and along the Alazan River Valley in Azerbaijan (Figs 1, 3-4). The road killed jungle cats can be found frequently along the Baku-Tbilisi highway in the same area. The jungle cat was photographed at least three times
(2013, WWF Azerbaijan) in these valley regions (Fig. 3).

Northern Azerbaijan is one of the northernmost parts of the species' range, and the Hyrkan NP is an area with a high density of the species, which makes these regions and Azerbaijan as a whole important territories for the protection of this increasingly vulnerable carnivore. The monitoring of the species in the mentioned areas continues and the latest data collected by us can help to assess the status of the species in the country.

\section{References}

Gray T.N.E., Timmins R.J., Jathana D., Duckworth J.W., Baral H., Mukherjee S. 2016 Felis chaus. The IUCN red list of threatened species.

https://doi.org/10.2305/IUC-

N.UK.2016-2.RLTS.T8540A50651463.en 

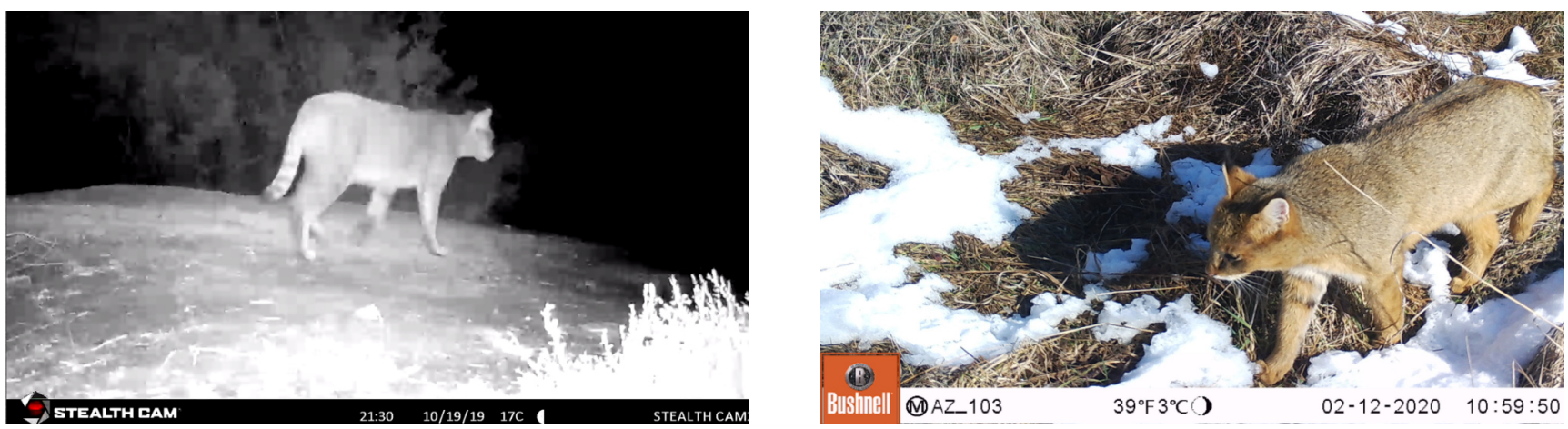

Fig. 2. Camera trap photos of Felis chaus: (a) [left] Korchay Reserve, (b) [right] Turyanchay Reserve.
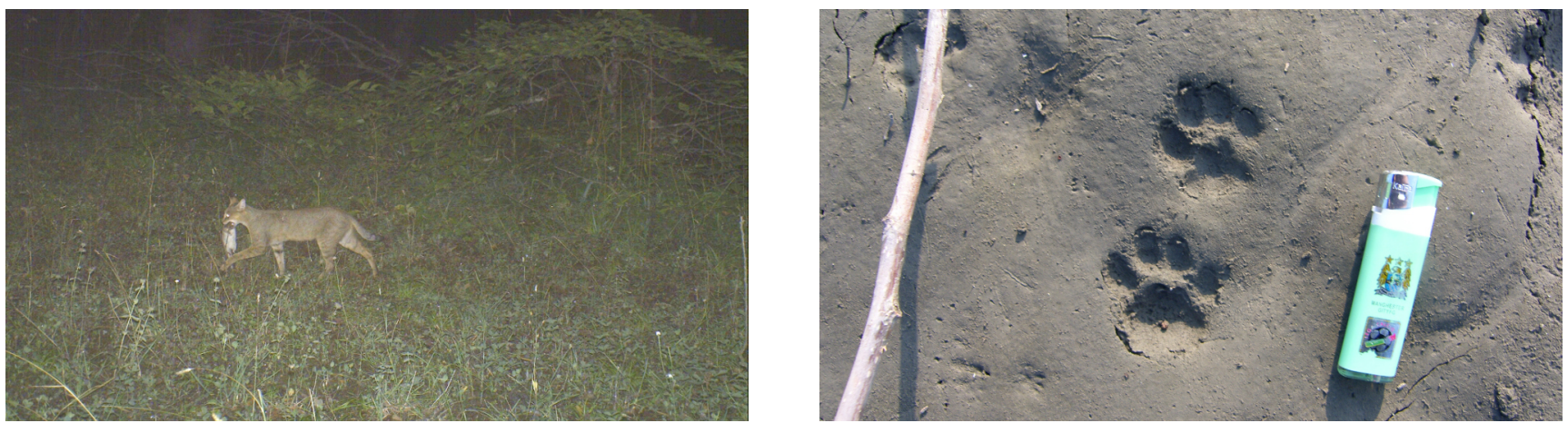

Figs 3-4. Felis chaus in Northern Azerbaijan lowlands: (3) [left] with fat dormouse (Glis glis) in its mouth, (4) [right] near the Alazan River, not far from the border with Georgia.

Hajiyev D.V., Rakhmatullina N.K. (eds) 2000 Animal world of Azerbaijan, vol. III. Baku: Elm S. 552-588. (In Russian)

Ogurlu I., Gundogdu E., Yildirim I.C. 2010 Population status of junge cat (Felis chaus) in Egirdir Lake, Turkey. Journal of Environmental Biology 31: $179-183$.

Qasimova N.I. 2013. Jungle cat, Felis (Chaus) chaus. In: Red Data Book of Azerbaijan Republic, Baku, 474-475.

Spassov N., Askerov E., Akosta-Pankov I., Ignatov A. 2020. New data on the occurrence of Panthera pardus in the Talysh Mountains, Azerbaijan (Carnivora: Felidae). Lynx, n. s. (Praha) 50: 113-118.

Ünal, Y., Eryilmaz, A. 2020. Jungle cat (Felis chaus Schreber, 1777) population density estimates, activity pattern and spatiotemporal interactions with humans and other wildlife species in Turkey. Applied Ecology and Environmental Research 18 (4): 5873-5890.
Yarovenko A.Y. 2014 Spatial distribution and population of the jungle cat (Felis chaus guild) in the Republic of Dagestan. International Scientific Conference Mammals of northern Eurasia: life in the northern latitudes, Surgut: 266. 